\title{
Supporting the Personal Knowledge Management of Students with Technology
}

\author{
Stuart Garner \\ Edith Cowan University, Joondalup, Australia
}

s.garner@ecu.edu.au

\begin{abstract}
Software-as-a-Service (SaaS) is the provision of computer applications over the Internet via a Web Browser. Examples of these services include Google Docs (2009) by which word processing, spreadsheeting, and presentation software are made available. Such software is often free, and also enables sharing and collaboration between users. It has developed rapidly recently and this paper discusses how such technology can support the personal knowledge management (PKM) of students, where PKM is defined as "a process and strategy for properly using the tools of technology for enhancing information, learning and inquiry skills" (O'Conner, 2002).
\end{abstract}

Keywords: Software-as-a-Service, personal knowledge management.

\section{Introduction}

There is currently a move to the use of low-cost laptop computers known as Netbooks (e.g., Acer, 2009). Such netbooks often do not have hard drives and rely on flash memory to store applications and data. Hence, storage capacity is more limited, however many applications no longer need to reside on computers as they can be provided via a Web Browser in what is known as the "Software-as-a-Service (SaaS) model. There is also a push, especially from Google, to provide storage for users' data on servers in this new "Cloud" computing model. All of these changes have implications for the personal knowledge management (PKM) of students during the learning process. Currently applications and data are stored on the hard drives of students' PCs, however this will not necessarily be the case in the future.

This paper discusses a model of student PKM and some of the SaaS applications which are now available, together with cloud computing storage facilities, that can be used within the model. It concludes with some suggestions for future developments in this interesting field.

\section{Personal Knowledge Management (PKM)}

Material published as part of this publication, either on-line or in print, is copyrighted by the Informing Science Institute. Permission to make digital or paper copy of part or all of these works for personal or classroom use is granted without fee provided that the copies are not made or distributed for profit or commercial advantage AND that copies 1) bear this notice in full and 2) give the full citation on the first page. It is permissible to abstract these works so long as credit is given. To copy in all other cases or to republish or to post on a server or to redistribute to lists requires specific permission and payment of a fee. Contact 0HPublisher@InformingScience.org to request redistribution permission.
It is difficult to define knowledge accurately however it is well agreed that knowledge is an organised combination of ideas, rules, procedures and information (Bhatt, 2000). When students learn, they gather information and then construct knowledge based on the knowledge that they already have. They are constantly adjusting their internal schemata as they transform information into 
knowledge. This is why constructivism is so important in teaching and learning as tutors look to ways to help students construct knowledge in the subject that is being "learnt" (Jonassen \& Reeves, 1996; Ring \& McMahon, 1997). Students have to make "meaning" of the information that they gather and by doing so the disorganised information becomes knowledge (Marakas, 1999 , p. 264). It is only through meaning that information finds life and becomes knowledge.

The more successful students are usually very adept at managing their own personal knowledge, and PKM has been defined to be:

A process and strategy for properly using the tools of technology for enhancing information, learning and inquiry skills (O'Conner, 2002).

With respect to PKM, O'Conner cites Norton and Sprague who state that

Today, all of us live and learn in a world that has been radically altered by the ready availability of vast stores of information encoded in a variety of formats. The learning process and the information process mirror each other as we seek to construct meaning from the sources we encounter and to create products that shape and communicate meaning effectively. Developing expertise in organizing and analyzing information is in fact the authentic learning that modern education must promote. (Norton \& Sprague, 2000)

Dorsey (2008) considers that there are seven components of PKM, these being:

(1) Retrieving information;

(2) Evaluating/assessing information;

(3) Organising information;

(4) Analysing information

(5) Presenting information;

(6) Securing information; and

(7) Collaborating around information.

The author has taken Dorsey's components and put them in the model shown in Figure 1 as to better reflect how students manage their personal knowledge. In this model: components 1 and 2 have been joined; components 4 and 7 have been joined; and component 6 has been shown that this should occur throughout the whole model. 


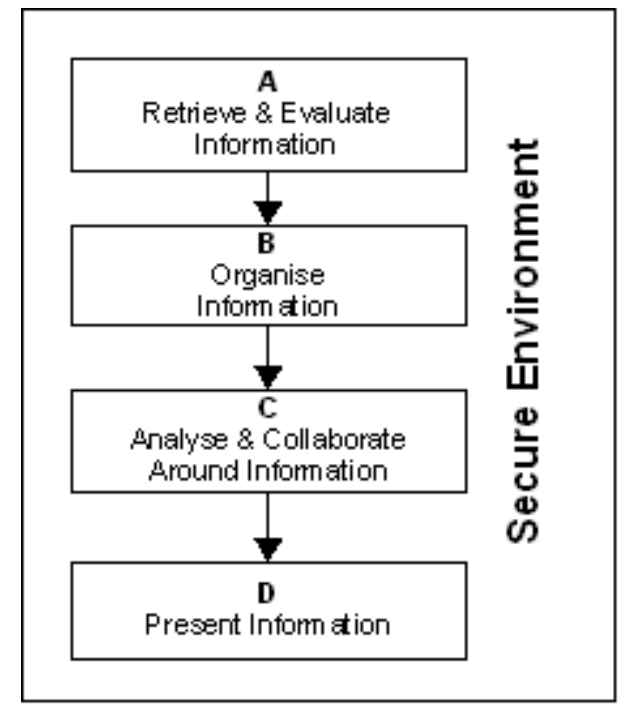

Figure 1: Personal Knowledge Management Model

To explain the model, consider the situation of a student at college or university who is assigned a task, such as the production of a research report and presentation. Such a task may be a group assignment involving collaboration with fellow students. Hence, the student(s) might begin by, [A], retrieving information from books, notes that they have already made in lectures, and of course the Internet. Such information would then undergo some initial evaluation to determine its usefulness for the given task in hand. The information would then need to be organised and stored for later use as shown at stage [B]. The information that has been gathered would then be analysed, and in a group situation, collaboration would take place to put together a "solution" to the task. It is at this stage [C] where higher order thinking would, hopefully, be taking place and knowledge being constructed. The final product [D] is where the information, or knowledge, is presented.

\section{Software-As-A-Service (SaaS)}

SaaS has been defined by Turban et al (2006) as situations where "Users can access applications over a network, with an Internet browser being the only necessity". Such applications are often paid for by a subscription fee, however many are free to the user and paid for by associated advertising. An example of SaaS is the search engine provided by Google.

Recently, this model has grown rapidly with many more such service providers having created diverse applications such as word processors, online notebooks, presentation tools, wikis, voice over IP telephony; white boards. In addition, online storage is now becoming available and so the reliance on "heavy" client computers is being reduced and a user can now utilise "netbooks" for most of their needs. The term cloud computing encompasses SaaS, however it is broader and also covers utility computing, and managed service providers who provide such functions as the virus scanning of emails.

\section{SasS Applications and PKM}

There are now many SaaS applications available that can be used by students to support their PKM. This section will discuss some of them with respect to the four stage PKM model. 


\section{[A] Retrieve and Evaluate Information}

When faced with a task or assignment, students need to gather information. That information may come from a variety of sources including textbooks, lecture notes, and in today's digital age, the Internet. The search engine of choice for the majority of students is Google, however there are more appropriate SaaS applications available to aid students in their searching.

In addition to searching the online databases that are available within university libaries, there is the specialised Google Scholar search engine (Google Scholar, 2009). There are also metasearch engines that utilise other search engines and often produce more relevant results. An example is Surfwax (2009) and a screenshot is shown in Figure 2. The search results are displayed in the left hand window and a summary is shown in the right hand window when the magnifying glass icon is clicked. Another metasearch engine that is popular is Dogpile (2009).

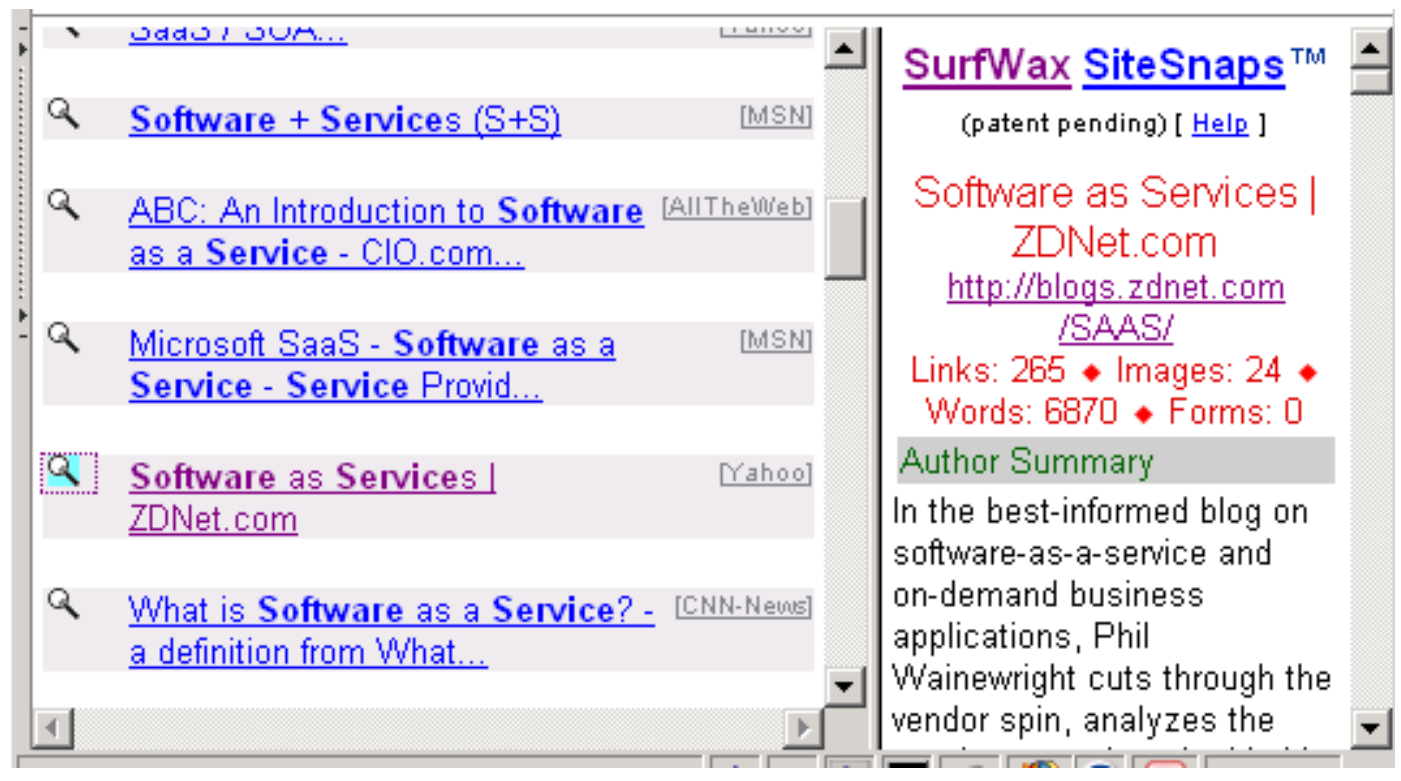

Figure 2: Surfwax

Determining useful and reliable information from online sources is often problematic and students are encouraged to make decisions based on the information source. A paper from a longstanding journal would be deemed to be more reliable than an entry from Wikipedia. The bookmarks of useful web pages need to be kept and these can be kept on servers within the "cloud". Google provides a Bookmark system and its advantage is that not only are bookmarks available from any computer, but the bookmarks can be searched with Google's well developed search capabilities and can also be shared.

The information that is found will be in the form of text, images, audios, and videos and notes would be taken from these sources prior to [B], organising the information. There are several online notebooks available including $\mathrm{ZOHO}(2009)$ which allows the pages to contain various information sources. An example is shown in Figure 3. 


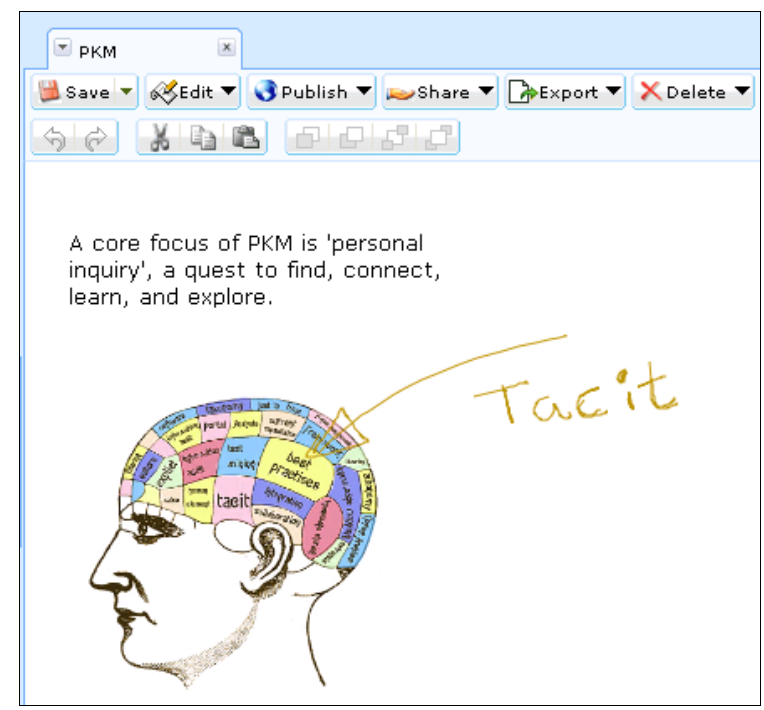

Figure 3: ZOHO Notebook Example

\section{[B] Organise Information}

It is recognised that the good organisation of information can help students in their learning. Tools such as ZOHO can help in keeping notes; however various files require storage and this, of course, is why computers have hard disks. In cloud computing, such storage is provided by virtual servers and an example is that of Adrive (2009) as shown in Figure 4.

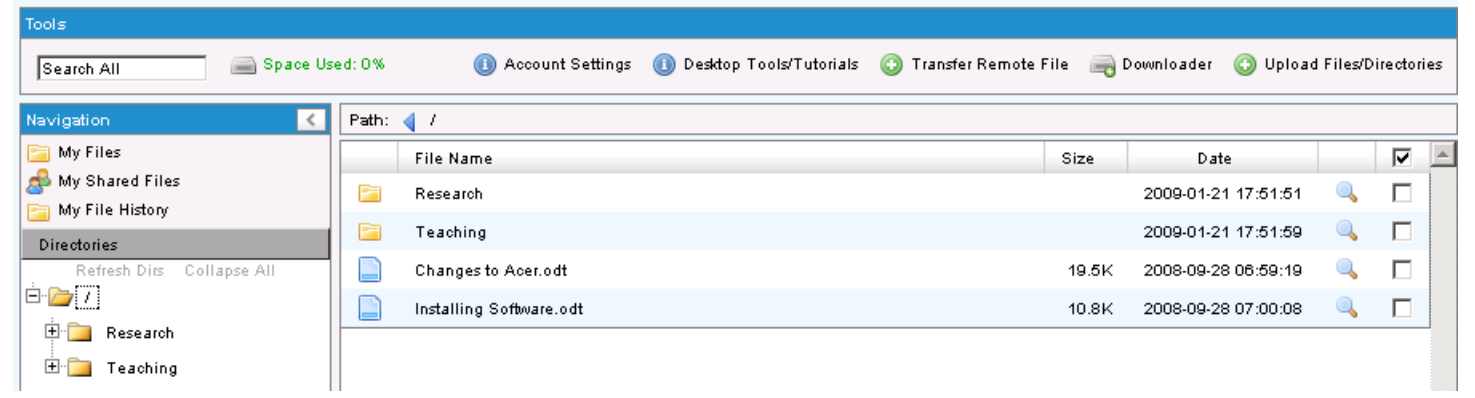

Figure 4: The Interface to ADrive

Figure 4 shows folders and files as displayed within a web browser. Fifty gigabytes are provided free by Adrive and certain premium services can be utilised via a subscription. There is currently talk about Google providing such services in the form of Gdrive, and it is suggested (Stuff.tv, 2009) that:

Google's GDrive would basically provide online storage through Google servers enough for the entire contents of your hard drive. You'd be able to access all your desktop files remotely, via a web interface, and there'd be tight integration with a host of Google services - Docs, Gmail, Picasa, etc

Many of the services that are now available permit information to be tagged thereby helping organise information and subsequently retrieve it. The information can usually be shared with other users. For example, a google bookmark can be tagged thereby allowing it to be "stored" in more than one folder, even though only one real copy is stored. In terms of information systems, there 
is a many to many relationship whereby a bookmark can be in many folders, and a folder can contain many bookmarks.

Additionally, some of the tools used in [C] to help analyse and collaborate, also have their own filing and storage mechanisms. A key example of this is Google Docs, one of the SaaS "office" type systems.

\section{[C] Analyse and Collaborate Around Information}

This is the phase where it is expected that students will engage in higher order thinking as they analyse the information that they have collected and organised for the assignment or task in hand in order to produce a "solution". In a group assignment, there would be much interaction between the students helping in knowledge construction as the tacit knowledge of some students is made explicit, or as existing fragments of explicit knowledge are combined to produce new explicit knowledge.

The notebook tools such as ZOHO can be shared over the Internet allowing a certain amount of asynchronous collaboration. The final product that is produced may well be a word processed document and there are several SaaS "office" type solutions available. Google Docs (2009) is one such example that provides word processing, spreadsheet and presentation tools. The big advantage for students is that a group is using just one copy of a document rather than using, for example, MS Word which requires the emailing of the document between members. A further advantage of Docs is that all changes that are made to a document are stored with details of when, and by whom, a document was changed. The document can be restored to any one of those original states. The submission of the final document to an instructor can be made by simply sharing the document with him or her. This also allows the instructor to see the individual contributions of the group members via the history of changes made.

There are various tools that can be used for synchronous communication between the members of a group. Internet relay chat has become ubiquitous and this also provides for voice communication via voice over IP (VOIP). Skype (2009) can be used for better quality VOIP; however, a new whiteboard tool provides the tools to discuss documents and also offers the interesting function of co-browsing (twiddla, 2009). This allows a group to view web sites in real time and then share ideas about the information shown. Figure 5 shows a Wikipedia page being marked up in real time allowing all participants / students to view this.

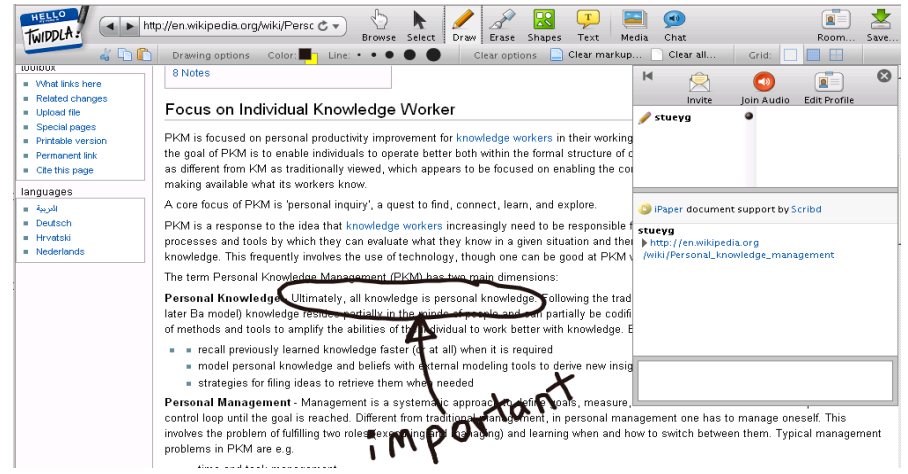

Figure 5: Example from twiddla.com 


\section{[D] Present Information}

The final component in the model concerns the presentation of information. In component $\mathrm{C}$, a document may well be produced by the use of word processing; however the presentation of students' knowledge is often in other formats. The most common requirement is that students make a presentation to an instructor and other students using presentation software such as Powerpoint. Such software is also available as SaaS, the best known being part of the Google Docs suite and an example is shown in Figure 6. Google Docs again allows the presentations to be shared, and there is also a site called SlideShare.Net which allows sharing with a wider audience. This site is the equivalent of YouTube for slide presentations and is shown in Figure 7.

Presentations can also be made via audio and video, with screencasting (Camstudio, 2008) becoming popular where a computer session can be captured in real time together with mouse movements, mouse clicks, and audio commentary. This does not yet seem to be offered in SaaS format, probably because it is resource intensive. There are free tools available such as Jing (2009) and CamStudio (2009), however these have to be installed on client computers.

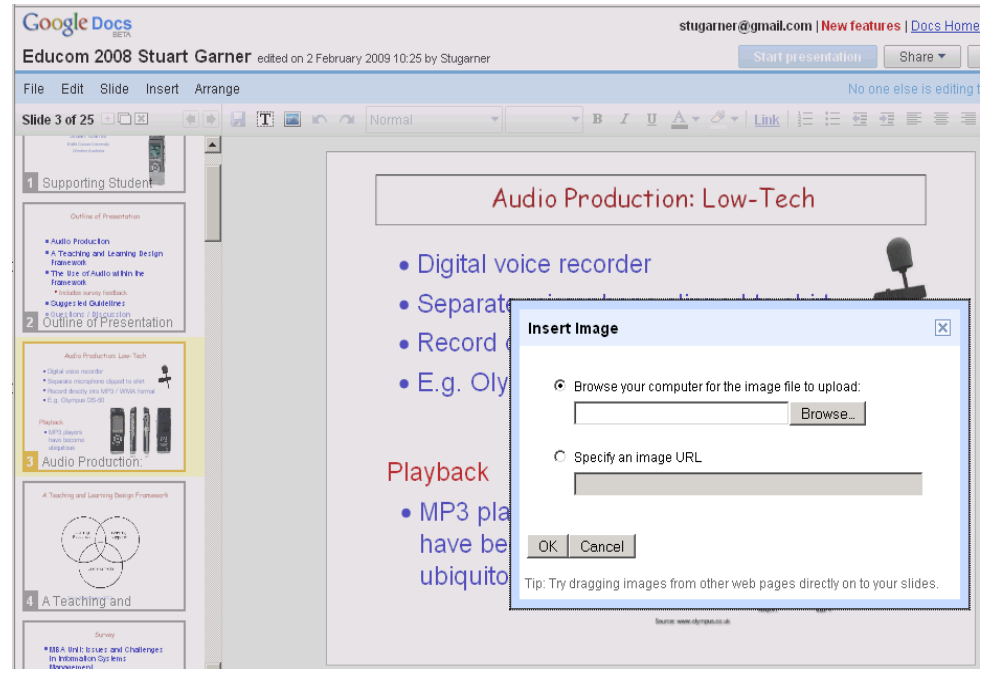

Figure 6: Google Docs Presentation SaaS

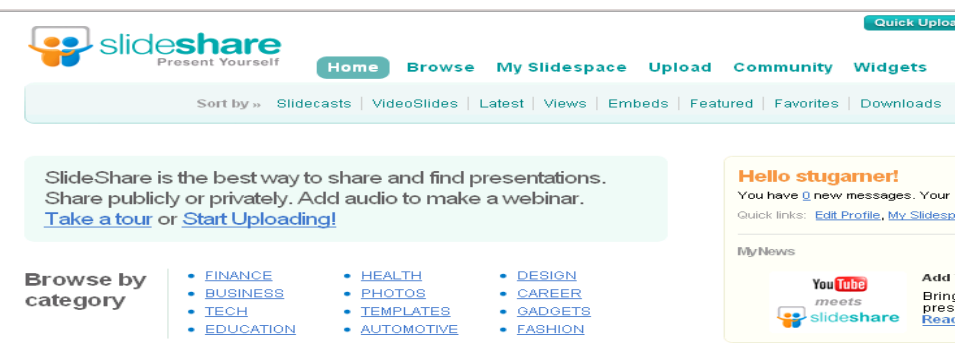

Figure 7: SlideShare for Sharing Presentations

\section{Securing Information}

All components of the model shown in Figure 1 need to be done in a secure environment. Security is a key issue with respect to SaaS as accounts can be compromised by hackers. Hence, as always, backups need to be made. One side effect of SaaS for students is that they tend to lose 
thumbdrives or have hard drive issues whereby important files are lost. Using SaaS generally provides a more reliable method of storing data for them.

\section{The Use of Wikis and PKM}

A wiki is a Web application whose content is collaboratively added, updated, and organized by its users (Mitchell, 2009). Wikis can be utilised in many areas including knowledge management within Business, and increasingly within Education. Several organisations are providing the tools to create and manipulate wikis under the SaaS model, one example being Google Sites (Google Sites, 2009). Such a tool can provide support for several aspects of the PKM model, particularly with components $\mathrm{C}$ and $\mathrm{D}$. Although information that has been retrieved can be pasted into a wiki page [A] and re-organised [B], the specialist tools described earlier generally do these aspects in a smoother manner. However, Sites is excellent in its support for collaboration around information [C] whereby any group member can make comments and amend that information, an audit trail being kept automatically. Figure 8 shows an example of a Google Site.

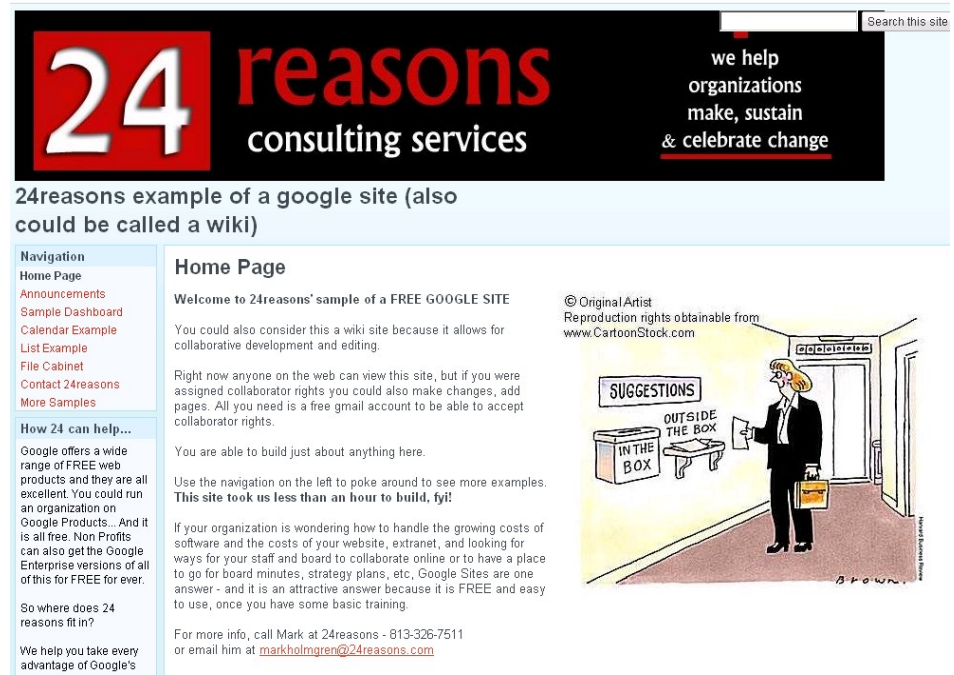

Figure 8: Google Site Example

Many iterations can take place such that eventually the information has been transformed into the "final" product that will be the presentation or assignment "submission". Nothing has to be physically submitted to a tutor. All that needs to be done is to make the wiki available to the tutor so that they can view it for assessment purposes. The final presentation [D] may just be a set of formatted web page and/or a Google Docs presentation which can be embedded in a wiki.

\section{Conclusions}

SaaS is the way of the future for software applications and rapid changes have been made. This paper has discussed how SaaS can help support students with their PKM by using a four component model. However there are issues to be overcome that will hopefully be addressed in the future.

One issue is that the successful implementation model relies on the Internet being ubiquitous whereas this is not the case. A student may wish to work on their Google document in a location without Internet access. To overcome this in the short term, some companies are offering downloadable solutions so that users can work offline. Google has Google Gears which is a Fire- 
fox and Internet Explorer extension that allows users to do work on compatible websites offline, and synchronize when going back online.

Google probably provides the best suite of tools and clearly has become a very dominant organisation. This concerns many as indicated by the following:

I know that Google is all about introducing new (usually useful) services which tie into its already existing sites and services, and for that I applaud it. However I hope that it takes privacy, security, and encryption into account for this new online storage service. It's one thing to do a search with Google's engine - trusting Google with personal files is another issue entirely (SlashDot, 2009).

In the future, it would be hoped that SaaS tools will be made available in educational content management systems such as BlackBoard (2009) as existing tools are often very "clunky". Also, some of these SaaS tools are being made available for the mobile phone, however for the serious work required in supporting students' PKM, the mobile phone is often perceived as unsuitable and that is why the netbooks have now become popular and will no doubt be further developed.

\section{References}

Acer. (2009). Retrieved from http://www.aspireoneuser.com/ [28/1/2009].

ADrive. (2009). Retrieved 23/1/2009 from http://www.adrive.com/

Bhatt, G. D. (2000). Organizing knowledge in the knowledge development cycle. Journal of Knowledge Management, 4(1), 15-26.

Blackboard. (2009). Retrieved 12/1/2009 from http://www.blackboard.com/

CamStudio. (2008). Retrieved 14/3/2008 from http://camstudio.org/

Dogpile. (2009). Retrieved 28/1/2009 from http://www.dogpile.com/

Dorsey, P. (2008). What is PKM? Retrieved 11/11/2008 from http://www.millikin.edu/pkm/pkm istanbul.html

Google Docs. (2009). Retrieved 26/1/2009 from http://docs.google.com

Google Scholar. (2009). Retrieved 26/1/2009 from http://scholar.google.com.au/schhp

Google Sites. (2009). Retrieved 23/8/2009 from http://sites.google.com

Jonassen, D. H., \& Reeves, T. C. (1996). Learning with technology: Using computers as cognitive tools. In D. H. Jonassen (Ed.). Handbook of research on educational communications and technology (pp. 693719). New York: Macmillan.

Marakas, G. M. (1999) Decision support systems in the twenty-first century, Englewood Cliffs, NJ: Prentice Hall.

Mitchell, S. (2009). Personal easy wiki hosting, Scott Hanselman's blog, and snagging screens. Retrieved 10/12/2009 from http://msdn.microsoft.com/en-us/magazine/cc700339.aspx

Norton, P., \& Sprague, D. (2000). Technology for teaching: Pearson, Allyn \& Bacon, 103.

O'Conner, M. (2002). Personal knowledge management (PKM). Retrieved 12/1/2004 from http://www.millikin.edu/webmaster/pkm/

Ring, G., \& McMahon, M. (1997). Web instruction: Searching for a theoretical basis. International Conference in Computers in Education 97, Kuching, Malaysia, pp. 220-228.

Skype. (2009). Retrieved 13/1/2009 from http://skype.com

SlashDot. (2009). Retrieved 14/1/2009 from http://tech.slashdot.org/article.pl?sid=09\%2F01\%2F30\%2F $2358215 \&$ from $=$ rss 
Stuff.tv (2009). Retrieved 14/1/2009 from http://stuff.tv/blogs/web/archive/2009/01/21/will-google-sgdrive-kill-off-the-desktop.aspx

Surfwax. (2009). Retrieved 28/1/2009 from http://www.surfwax.com/

Turban, E., Leidner, D., Mclean, E., \& Wetherbe, J (2008). Information Technology for Management: Transforming Organizations in the Digital Economy (6th ed.). Wiley.

Twiddla. (2009). Retrieved 29/1/2009 from http://www.twiddla.com/

ZOHO. (2009). Retrieved 3/1/2009 from http://www.zoho.com/

\section{Biography}

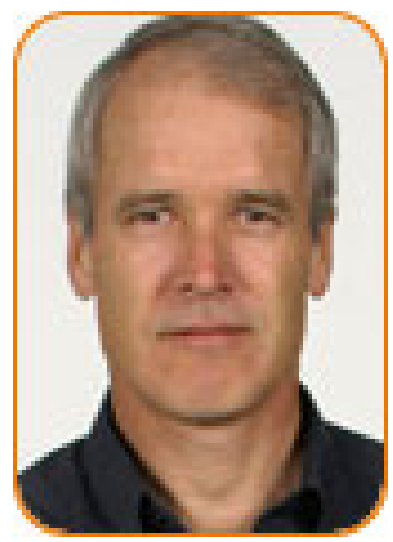

Stuart Garner has been a college and university lecturer for over 30 years and has also spent time working in industry as an analyst programmer. His main research interests include: the teaching and learning of programming; the teaching and learning of systems analysis and design; eLearning; personal knowledge management; and web based development.

Stuart is currently a senior lecturer in information systems at Edith Cowan University, Western Australia. His profile is available at: http://www.business.ecu.edu.au/schools/man/staff/sgarner.htm 